\title{
CIDADES INCAPAZES
}

\author{
CÁSSIO EDUARDO VIANA HISSA ${ }^{1}$ \\ CARLA WSTANE ${ }^{2}$
}

A cidade das palavras extintas

Está à espera que algo importante

Chegue em silêncio

(Boaventura de Sousa Santos)

Resumo: A cidade carrega consigo muitas definições. Isso se dá não apenas porque há cidades de todas as espécies, mas, também, porque há cidades nos interiores da cidade. A cidade é o mais expressivo dos lugares que, por sua vez, são expressões de mundo. O mundo se realiza nos lugares e a cidade é o mundo a se expressar de modo mais intenso. A cidade é desenhada através de artes de fazer. No entanto, a cidade moderna, globalizada, é a expressão de um mundo bipartido. Assim, a cidade moderna, predominantemente a do desencontro e do desfazer — a cidade do descarte imediato - , poderá ser compreendida como a expressão contraditória e dialética, de um lado, de mundos hegemônicos de racionalidade e, de outro, de fazeres de arte: mundos que se negam e existem, também, em virtude dessa negação. A cidade moderna é o lugar das pressas interrogadas, nos seus interiores, pelas cidades incapazes, a dos homens lentos. As cidades incapazes são os lugares da indignação, do desejo de transformação, da incompletude assumida que, paradoxalmente, se estende à medida que vai se reproduzindo a arte de viver.

Palavras-Chave: cidades; escrita da cidade; cidade e literatura; escrita INKZ; cidades incapazes.

Professor do Programa de Pós-Graduação em Geografia da UFMG; Mestre em Demografia pelo CEDEPLAR / UFMG; Doutor em Geografia pela Universidade Estadual Paulista; pós-doutorado em Sociologia e Epistemologia pela Universidade de Coimbra.

2 Bacharel Licenciada em Geografia; Especialista em Estudos Ambientais pela Pontifícia Universidade Católica de Minas Gerais; Coordenadora do Projeto de Educação Ambiental: Integração Comunidade/Escola do Núcleo Integrado Cascatinha, desde 2005. 


\section{Introdução: a cidade da perversão da arte}

Se a cidade é sempre lugar - ou espaço de lugares —, ela nem sempre foi a cidade da técnica e da razão cartesiana. A cidade moderna, global, é, sobretudo, a expressão da cidade da técnica, da razão, das geometrias retas que aparam e suprimem as curvaturas das praças. A partir de então, as esquinas e praças, que simbolizam encontros, se transformam em lembranças guardadas pelos seus nomes gravados nas placas de trânsito. Se a cidade moderna é, sobretudo, a expressão da técnica e da razão, ela é, também, a expressão da perversão da arte. Porque a razão que assalta a cidade - e lhe rouba ou lhe esconde experiências, práticas e sabedorias - é a perversão da arte. A cidade moderna, portanto, não é mais apenas o lugar dos fazeres artísticos, mas, seletivamente, o lugar da apressada razão a roubar o tempo das artes de fazer para pensar e agir, a roubar o tempo de experimentar para viver.

Poderíamos pensar um verbete de definições breves para apenas um objeto. Cidade: rede de lugares de existências, de densidades e de superfícies corpóreas. Lugares de movimento, de pressas, lentidões, pausas, asfixias e paralisias. Redes de encontros e territórios de desencontros. Lugares de vazios, desertos, sertões. Espaços do conhecimento, saberes e sabores. Territórios da razão. Lugares de afeto, de vivências, de experiências. Espaços de limites, de fronteiras e sobrevôos, de todas as espécies, que fazem ver o que do terreno é invisível. Lugares de perguntas e territórios de respostas. Territórios de fortes questões e de frágeis respostas provisórias. Lugares de derrotas sobre as quais não se fala: derrotas invisíveis. Lugares de expressão, de ação. Territórios de conquistas de poucos, quando muitos experimentam esquecimentos e fracassos. Cidade para poucos e de muitos. Moderna cidade, metrópole, globalizada cidade feita de teoria do planejamento e de prática política excludente. Cidade, também, de práticas de todas as espécies que fazem a existência e o existir na cidade e nos lugares da cidade; nas cidades da cidade. Espaços de técnica e de arte. Territórios de saberes desqualificados que, por sua vez, fazem a vida que, também, ignora a ciência. Saberes de arte. Arte de viver e de sobreviver. Arte de dar vida aos corpos de todas as espécies. Corpos-paisagem, lugares-cotidianos, territórios de possibilidades e significâncias. O verbete imaginado, de breves notas, de um só objeto, expressa contradições. A cidade é, também, feita dessas contradições e, em muitas circunstâncias, se expressa através delas. 
Na cidade - rede de lugares, espaços de vivências, de arte, técnicas ou de racionalidades conservadoras —-, as experiências são mescladas, as impressões se fundem, as marcas deixadas se adentram pelos becos, ruelas e se perdem nos vazios das avenidas. Ali se materializam todas as formas de expressão humana e suas interferências: grafias e técnicas imprimem as estampas do tecido urbano. O que se pode dizer ainda da cidade:

\section{[...] é o lugar da criação, da fertilização. A cidade, o lugar da vida moderna, também, é o espaço da arte; o lugar da vida, contraditoriamente, é o lugar da exclusão, dos sonhos frustrados e da marginalidade. O espaço da arte é o da sua negação. Lugar do encontro, espaço inventado para a palavra, a cidade é a praça. (HISSA, 2008, p. 269).}

O espaço que agrega, entretanto, é o mesmo que exclui. As topografias sociais da cidade são expressões metafóricas de um relevo feito de ondulações, de saliências, mas, também, de concavidades, de fluxos rápidos e, contudo, de passos de homens lentos, como a eles se referiu Milton Santos (1996, 2000, 2005). O lugar que cria, imita a arte e se refaz através dela; recria a vida na tentativa de superar as imposições de um único pensamento segregador, imposto pelo mundo globalizante ou, dito de outro modo, como preferiu Milton Santos (1996), imposto pela racionalidade global. As subjetividades, registradas no tecido urbano, através, por exemplo, dos grafites - expressões da arte urbana -, dialogam com o anacronismo dos fluxos de tempo, de formas diversas, de cores que se ajuntam aos corpos e lhes concedem significados sempre voláteis, mutáveis.

Arte e técnica - subjetividade e racionalidade - fazem parte do movimento dos lugares da cidade. Movimentos que não cessam, e, sim, criam e recriam complexas interações, intensificadas pelo agir humano no ambiente. $\mathrm{O}$ enlaçamento entre essas duas formas de expressão, subjetividade e racionalidade, abre um infinito de possibilidades de experiências e de práticas, sempre ainda mais criativas, do viver humano no mundo. Porém, na cidade contemporânea, subjetividade e racionalidade foram supostamente apartadas para dar lugar à praticidade do conhecimento prometido pela ciência moderna. Assim, nos lugares da cidade, no imediatismo, compreendem-se mais as funcionalidades práticas do que a corporeidade estética e ética. Talvez, a compreensão da corporeidade estética e ética ceda espaço para as diversas demandas da praticidade e da funcionalidade. Assim, a cidade moderna estabelece uma 
relação de correspondência com a ciência moderna, com a técnica e a razão que objetivam a fabricação de espaços de trânsito e de passagem estéril.

O lugar da ciência não é mais o lugar da arte. É o que parece ser. Porque a ciência moderna, para que se reafirme, procura deslegitimar todas as espécies de arte de modo a se qualificar como ciência (HISSA, 2009). Do mesmo modo, há uma espécie de revanche: a arte também se põe a negar a ciência para que se afirme como arte. Ambos os movimentos de negação não se reconhecem, contudo, como atitudes que esvaziam os saberes de prática, de experimentação, crítica e estética. A inversão da equação interpretativa também conduz à idéia de que os movimentos das referidas atitudes ainda esvaziam as práticas de sabedoria, de experimentação e de crítica. Assim, através da consolidação da reciprocidade das sublinhadas atitudes, legitima-se o limite, em detrimento do fortalecimento das aberturas necessárias à construção de sabedorias. A cidade moderna, ainda que pelas suas margens que ultrapassam molduras, vai se fazendo através da arte de experimentar o mundo - ou da arte de viver - que, contraditoriamente, é negada pela cidade hegemônica, referenciada pela racionalidade global disseminada através da prática de perversão da arte. Essa prática é constituída pela negação da sabedoria de viver e de conviver.

Por conseguinte, ao também negar a arte de conviver, a cidade moderna é a expressão espacial da perversão da arte. Racional, moderna, hiper-moderna, a cidade controla a arte e, no imaginário coletivo, diz para todos onde é que a arte vai se apresentar. Ela se apresentará, por exemplo, nos muros da cidade. É uma arte comum, banal, um fazer cotidiano que poderá ser mesmo arremedos de arte. Ainda que até mesmo o arremedo seja arte - porque, a despeito de tudo, o fazer na cidade é tudo arte —, na cidade da pressa, ele é a arte domesticada. Uma arte domesticada e, portanto, esvaziada de conteúdo crítico. Arte corrompida e que se deixa corromper para estar no seu destino. Mais além, é a própria arte pervertida - que na cidade encontra a sua espacialidade -, no seu fazer, que, também, corrompe a todos. A pressa da cidade hiper-moderna ainda obstrui a compreensão de que a domesticação da arte é, também, a domesticação da vida, da existência, da convivência, do encontro. Até o acaso poderá ser domesticável, na cidade global. Poderá ser tudo assim. Contudo, há cidades na cidade. Há cidades lentas na cidade. Há resistências e, com isso, a perversão da arte, a ciência - a racionalidade que procura fabricar cidades funcionais, através de instrumentos de regulação, das gestões e das administrações de discursos aparentemente 
retos - , encontra também as suas armadilhas. A cidade não é mesmo a cidade inteira. Ela é feita de recortes e, assim, poderá ser compreendida, também, como o espaço da pressa que encontra a lentidão; ou o espaço da perversão da arte que, em alguma esquina, encontra modos diversos de fazer a arte que se reinventa e recria possibilidades de vida digna.

\section{Arte e racionalidade nos lugares}

A distinção entre as práticas de fazer poderá ser compreendida como um resultado das transformações do mundo, mas, sobretudo, como uma expressão política e ideológica que distingue exercícios interpretados a partir de referências distantes. Assim, em primeiro lugar, a cidade da arte será, supostamente, diferente da cidade da técnica, ainda que estejamos nos referindo à mesma cidade a partir do seu traçado geométrico em que ela vai se escrevendo, rascunhando e se rasgando em pedaços para se reproduzir, disseminada. Em segundo lugar, a cidade da técnica é o espaço-tempo que não apenas torna invisível a cidade da arte como, também, desqualifica ou desconsidera a cidade da arte de viver e de experimentar o mundo. A cidade da arte é a expressão de práticas de fazer referenciadas por paradigmas que até poderão ser compreendidos como contra-hegemônicos, ainda que a arte, também, requeira, do mundo, a sua canonização em relação à racionalidade predominante. A cidade da razão é a expressão de práticas de fazer referenciadas por paradigmas hegemônicos, que, na contemporaneidade das cidades globais, até poderão ser interpretados como referências de uma hiper-modernidade em processo de propagação. A cidade da razão é aquela das avenidas, das luzes fulgurantes, das grandes aberturas vazias que, percorridas pelos fluxos, pelos trânsitos das pressas, constrói a imagem da velocidade a construir vazios. A cidade da razão é aquela que se vende como a imagem do progresso contemporâneo, hiper-moderno, conectada em uma complexa rede a partir da qual ela é vista com uma moldura que lhe retira os lugares sem preço ou os lugares de descarte mais imediato.

A cidade que se vai fazendo é a expressão dos tempos que vão se acumulando e se expressando nos lugares. Porque a cidade é cidade-tempo, uma representação de espaços-tempo. O anacronismo da história e do tempo está incorporado nessa cidade que se vai fazendo aos lugares, ou aos tempos, ou passo a passo, nos ritmos descompassados das artes de fazer. Isso significa, também, que a cidade não se faz na sua inteireza, a um tempo só, mas ela se faz anacronicamente, nos lugares da inteireza 
idealizada, presente nas cartografias ideais que preenchem os imaginários e os desejos de ter o mundo nas mãos ou nos mapas. Assim, como não há a cidade inteira, também não há a cidade que se faz completa e a um tempo só. A cidade é sempre incompleta, e vai se resolvendo no ritmo dos fazeres distintos, tal como são compreendidos, em sua distinção, desde que eles estejam subordinados à prevalência da racionalidade cartesiana em detrimento das subjetividades.

Há o conhecimento do mundo da cidade dos que o compreendem aquém dos muros da universidade. Há, também, o conhecimento do mundo da cidade através dos que o compreendem a partir dos seus terrenos, no desenrolar do cotidiano. São mundos que, aparentemente, se negam ou se rivalizam. Contudo, ainda assim, é nítido, estampado no espaço, um emaranhado de tessituras inspiradas tanto pelas artes como pelas racionalidades técnicas. Do mesmo modo, é também nítido, nesse estampado - que se faz de certa pedagogia das tipologias — que a cidade da arte é distinta da cidade da razão. Entretanto, já parece claro que a compreensão da cidade, em seus variados recortes, estará à espera de vozes híbridas feitas de arte e ciência. Haverá quanto tempo de espera? A espera da qual se fala não será traduzida em fazer?

Em decorrência da percepção de que as trajetórias de compreensão da cidade serão mais frutíferas a partir desse entrelaçamento, tem sido crescente o número de escritores, autores que tentam resgatar o encantamento pela vida, incorporando a diversidade de formas de expressão presente nos lugares do mundo. São artistas que dialogam com cientistas ou conceitos científicos na produção de suas obras. São crescentes, também, as clarezas das possíveis relações entre diferentes linguagens artísticas e científicas no processo de criação, tanto da ciência quanto da arte, a partir de poemas, cartografias, desenhos de recortes de cidade, instalações artísticas, mapas de palavras, protótipos etc.

A arte anunciada de diversas formas nos ambientes da cidade através da música, das artes plásticas, da poesia, da literatura permite "a liberdade [que] exterioriza-se na compreensão das relações entre todos os saberes. Na criação ela reflete a formação e o espírito abertos, indispensáveis à construção da crítica. [...] É no sujeito que cria que a liberdade se projeta”. (HISSA, 2002, p. 139). A recuperação da arte, pela ciência - ou a compreensão da ciência como uma espécie de arte que, pervertida, procura se reencontrar - permitiria pensar a fabricação da cidade noutros termos e a partir de outras referências. Já observara Milton Santos (1994) que a 
geografia perdeu ao se desvencilhar da arte, da literatura, da poesia, da filosofia, mas, com isso, perderam todos os saberes e conhecimentos, tanto a arte quanto a ciência. A cidade dos homens, a partir de então, é reconhecida, hegemonicamente, como a cidade da racionalidade.

A ciência, no exercício de conhecer o mundo, incorporou em suas práticas a tentativa de separação entre razão e emoção, e, por isso traz consigo um discurso carregado de certezas e respostas para as complexas questões da vida, em que tudo é enquadrado em modelos teóricos, leis, normas e técnicas. E, assim, permite-se desconsiderar o que é revelado na ação subjetiva do cotidiano, materializado na arte do lugar, nos fazeres dos lugares, nas vivências expressadas pela cultura. Contudo, as vivências humanas são mostradas a partir da ação criativa e fecunda de comunicação através da arte escrita, falada, estampada, pintada, esculpida nos lugares das cidades pelos sujeitos do mundo. Lê-se com Milton Santos:

O lugar é o quadro de uma referência pragmática do mundo,
do qual lhe vêem solicitações e ordens precisas de ações
condicionadas, mas é também o teatro insubstituível das
paixões humanas, responsáveis, através da ação
comunicativa, pelas mais diversas manifestações da
espontaneidade e da criatividade. (SANTOS, M., 1996, p.
258).

Razão e emoção estão juntas nas pessoas pelos lugares da cidade. Humberto Maturana pensa o papel das emoções no viver humano no cotidiano. Para ele, o comportamento humano é perpassado pelo referencial da emoção e da linguagem: "Todo sistema racional tem um fundamento emocional” (MATURANA, 1998, p. 15). Ainda: “o humano se constitui no entrelaçamento do emocional com o racional" (MATURANA, 1998, p. 18). Milton Santos discorre sobre o papel da proximidade e da troca, na constituição de palavra inventada a partir das experiências da existência. Emorazão:

O intercâmbio efetivo entre pessoas é a matriz da densidade social e do entendimento holístico [...] constituem a condição desses acontecimentos infinitos, [...], matrizes de trocas simbólicas que se multiplicam, diversificam e renovam. A noção de "emorazão" [...] encontra fundamento nessas trocas simbólicas que unem emoção e razão. (SANTOS, M., 1996, p. 256). 
Os fundamentos emocionais dos sistemas racionais, tal como pensa Humberto Maturana, tem significados importantes para o argumento: experimenta-se para pensar. O pensamento é tributário da experimentação do mundo, do sentir o mundo, tal como ainda sugere Humberto Maturana (1997). A partir da referida tese, encaminha-se a idéia de que $a$ arte faz a razão, a ciência, as tecnologias e a técnica. Não é sem motivo que se pode refletir acerca do surgimento - e mesmo da natureza do surgimento - da crise da razão que, em princípio, dar-se-ia com a própria estruturação do pensamento racional ou, simplesmente, com a própria razão. "Um pouco como se o verme fosse co-natural à maçã.” (PRADO JÚNIOR, 1996, p. 111). As subjetividades fazem a existência da razão que, por sua vez, configura-se como arte corrompida. A cidade se apresenta, também, como a espacialização contraditória e dialética que envolve artes e racionalidades. Há, na literatura, também, trajetórias de conciliação entre arte e ciência, como se fosse o caminho a percorrer de modo a conciliar a cidade da pressa e a cidade dos homens lentos. Em Seis propostas para o próximo milênio, Italo Calvino se apresenta:

No universo infinito da literatura sempre se abrem outros caminhos a explorar, novíssimos ou bem antigos, estilos e formas que podem mudar nossa imagem do mundo... Mas se a literatura não basta para me assegurar que não estou apenas perseguindo sonhos, então busco na ciência alimento para as minhas visões das quais todo pesadume tenha sido excluído... (CALVINO, 1990, p. 19-20).

Trata-se de um Calvino pensador, filósofo, amante clandestino da epistemologia, vinculado à literatura que faz pensar. Ele está próximo de Roland Barthes (2007, p. 12), para quem o "objeto em que se inscreve o poder, desde toda eternidade humana, é: a linguagem [...]”. A linguagem estará sempre ligada à situação de poder. Quem fala, escreve e se expressa artística ou cientificamente tem o poder de indicar caminhos e de fabricar, manipular, reinventar idéias. A literatura possibilita atribuir características subjetivas e simbólicas à linguagem e, também, permite dar voz ao desenho espacial que se vai fazendo pelos sujeitos dos lugares. Nas narrativas literárias de todo o mundo, podem-se encontrar descritos vários tipos de saberes: geográficos, históricos, antropológicos, artísticos, técnicos etc. "A literatura assume muitos saberes [e] todas as ciências estão presentes no monumento literário” (BARTHES, 2007, p. 17). Para quem pensa a ciência como a perversão da arte, está aí uma concepção de arteciência que interroga a perversão. Conto, romance, ensaio ou poesia: os 
textos literários podem instigar a imaginação, a criação de infinitas interpretações, a criatividade e o questionamento. “A leveza dá matéria às idéias que fluem livremente pelo texto, sublinha e evidencia o pensamento, fornece as melhores imagens" (HISSA, 2002, p. 196). O texto poético geralmente cheio de criatividade possibilitaria a escrita das complexas relações estampadas no espaço, se assim a ciência moderna o permitisse. É o que se deseja para a cidade da vida que se vai escrevendo com a leveza de quem experimenta o bem viver. Trata-se do sentido oposto da cidade da razão, onde prevalece o peso das competitividades e das aniquilações.

Caminhos de razão e emoção que se cruzam devem ser explorados na busca de respostas aos questionamentos do viver humano. "O sabor das palavras, quando não está contaminado pelas ilusões provocadas pelo anseio de objetividade, é o ingrediente do discurso fecundo e permite a aventura da ciência, através da imaginação” (HISSA, 2002, p. 190). A escrita científica, portanto, deveria ser carregada de sabor, imprescindível para o desenvolvimento de um texto que inspire o saber fecundo e estimulante. E que consiga trazer à tona as emoções do cotidiano estampados nos lugares da cidade. Do mesmo modo, a escrita da cidade deverá incorporar o sabor de viver e, certamente, a partir de outras referências que redesenham a racionalidade e que a submetem a um novo paradigma. Qual é a escrita da cidade que nos devolve o lugar das palavras de encontro?

\section{Arte incapaz na cidade do desfazer}

Poderá haver aquele sociólogo ou jurista que, ao mesmo tempo, seja poeta, artista ou músico. Quando assim é, sob as referências dos paradigmas da hiper-modernidade - a regular os fazeres e as práticas dos lugares, a dizer a todos o que deve ser e o que não pode estar -, a poesia do sociólogo, mesmo tendo óbvias virtudes maiores, poderá fazer, através dos cânones, com que a racionalidade desqualifique a qualidade da sua virtuosa interpretação sociológica. Do mesmo modo, contraditoriamente, mas compatível com a lógica da inversão das atitudes, já mencionada, a poesia do jurista ou do cientista social, para não dizer da poesia do físico, é desqualificada, também, pela própria racionalidade estética que não se admite mestiçada ou contaminada pelo fazer da ciência. Assim, vai se percebendo que os mundos não se desejam e que há reciprocidade nos processos de desqualificação. Entretanto, a validação crítica que 
deslegitima é mesmo desqualificada, no sentido em que não carrega virtudes e tampouco argumentos. Porque a poesia poderá estar em toda parte. Não apenas nos versos ou nos poemas. Talvez, mais acertado poderia ser a interpretação a encaminhar a imagem de que todos os fazeres são feitos de arte e que, a partir daí, toda a crítica que desqualifica a poesia ou a ciência, carregada de poderes canonizados politicamente, muitas vezes de modo corporativo, é mesmo esvaziada da virtude maior: a de conter argumentos e consistências.

Assim, os cânones voltam os seus olhos para a poesia do físico e a interroga, como se o físico não carregasse em si a poesia, ou não pudesse carregá-la. Ou como se o físico fosse um impertinente invasor de territórios, desprovido de músculos para arrastar a poesia que ele também fabrica com o seu corpo de físico no mundo, como se fosse algo a ele estranho ou como se ele fosse feito apenas de seu corpo de físico. Então, outra imagem poderia mesmo se fazer: como se a poesia fosse algo tão leve diante da física, que, sendo proferida pelo físico, se tornasse pesada para ele. A partir daí, os cânones também voltam os seus olhos para a física de mesma autoria e a interroga, a desqualifica, com a desconfiança de que possa estar contaminada pela poesia. Finalmente, os cânones, que representam o fechamento de práticas e de fazeres, ou o limite de experimentações, voltam os seus olhos para encaminhar o seu talvez definitivo parecer acerca da suposta, possível e necessária divisibilidade das coisas e dos homens. O mundo, assim, poderia ter o seu início feito de um fim: a cidade teria um propósito, um destino e um fim, sendo feita de homens classificados pelo que fazem ao fazer a cidade. A cidade de homens divididos em tipologias ainda seria feita de homens divididos em partes, em porções que supostamente não se misturam. É precisamente no limite que separa as metades que residem fronteiras a mostrar aberturas para onde seguem as cidades. Os lugares da cidade seguem para onde se apontam as aberturas anacrônicas, de tempos que não coincidem e de ritmos que se desafiam. É assim a cidade moderna, hiper-moderna, globalizada, incapaz, bipartida, de homens mutilados, vigiados, engavetados nas tipologias. Entretanto, as aberturas existem e, para lá, segue a cidade dos homens de utopia.

Há homens da cidade de aberturas que assumem os riscos, postos pelos olhos dos cânones, ou enfrentam as armaduras das tipologias: "procuro o reencantamento, que já não pode ser só pela arte, não pode ser só pelas ciências sociais - talvez pelas duas, juntas, seja possível" (SANTOS, B., 2008, p. 4). Talvez, além disso, possa-se não apenas pensar 
a possibilidade de assim ser, mas pensar que de fato seja assim: todos os fazeres são arte. Entretanto, há uma máquina, na cidade, fabricada nos tempos modernos, cuja finalidade é desfazer. Assim, há o desfazer da unidade das práticas e dos fazeres. Este é o desfazer que faz o princípio de todas as partilhas mutiladoras da cidade dos homens que fazem. Entretanto, abre-se, também, o espaço para a existência da cidade excludente que se percebe, aos olhos do intérprete ingênuo, como o mais capacitado dos lugares. Nela, entretanto, tudo é efêmero. Nada parece durar. Tudo parece ser feito para se desmanchar. O que parece velocidade poderá ser mesmo paralisia. São Paulo e Nova York são paralisias ou representações de espaços-tempo anestesiados onde nada parece existir sob a referência do descarte iminente. A incapacidade de dissolução do descarte nos traz o terror do descarte cotidiano dos homens mutilados pelas máquinas de desfazer. Entretanto, há espaços de resistência ou territórios de utopia. Na cidade globalizada, há cidades incapazes. Elas são processadas, dialeticamente, no mesmo ritmo produtivo da máquina de desfazer. A partir de então, pode-se refletir mesmo sobre a natureza da referida máquina de desfazer: na cidade moderna, globalizada, é ela a efetiva máquina de fazer. Fazer é desfazer, e, nos interiores da cidade anestesiada resiste a cidade incapaz.

A cidade incapaz é lugar de arte incapaz. A cidade incapaz está próxima do que se denominou, aqui, de cidade da arte. Ela poderá fazer-se mais forte na cidade do desfazer, do descarte, desmonte, nos lugares da efemeridade mais imediata. Poder-se-ia refletir acerca da capacidade de produção da máquina de desfazer que, também, é uma máquina de produzir efemeridades imediatas. Entretanto, a máquina de desfazer produz efemeridades imediatas à medida que, dialeticamente, são processadas, à revelia das máquinas e das racionalidades hiper-modernas, efemeridades menos imediatas e, assim, fazem existir formas mais permanentes no corpo social da cidade. Do mesmo modo, na cidade do desfazer, onde também se fazem cidades incapazes, as máquinas de desfazer produzem efêmeras imagens de marketing e, de outra parte, a existência de imagens para a mecânica global. Assim, na cidade paralisada, aparentemente feita de pressa, há cidades incapazes, lugares da diversidade de possibilidades de arte ou de fazer, de inovar, de experimentar a vida com a potencialidade dos homens lentos ou dos homens pobres do Sul Global. Tal como a arte incapaz, a cidade incapaz "não se contém em si própria” (SANTOS, B., 2004, p. 12). Tal como os homens lentos, ela é lenta ou até aparentemente imóvel “[...] para que tudo o mais se mova.” (SANTOS, B., 2004, p. 12). É 
mesmo assim: a velocidade é medida a partir do imobilismo. E as cidades anestesiadas, grandes complexos globais, adquirem tal adjetivo, contraditória e dialeticamente, em razão do imperceptível não-movimento que procura esconder o fazer cotidiano, a solidariedade, a co-presença, a própria racionalidade dos lugares nos interiores da grande densidade. A cidade incapaz é como a arte incapaz: "não se sustenta nem se completa por si própria” (SANTOS, B., 2004, p. 12). Tal como a arte incapaz, a cidade incapaz é um lugar da cidade, como lugares de arte, que, talvez, antes de tudo, seja mesmo o espaço aberto para a manifestação dos outros e, sobretudo, a expressão dos outros em nós. Por tal razão, a cidade incapaz é um contra movimento em relação às hegemonias das cidades globais, confortavelmente caracterizadas pelas suas digitais e infinitas conexões, pelas suas pressas, aparentes, medidas mesmo a partir das imobilidades que fazem a sua natureza e a natureza das suas máquinas de desfazer.

Na obra poética intitulada Escrita INKZ, o escritor português Boaventura de Sousa Santos inclui vozes da sua teoria social. São fortes vozes. Elas são estruturantes, de alguma maneira, da obra poética. Mas a fenomenal obra sociológica e epistemológica de Boaventura de Sousa Santos parece não comportar a poética explícita. Mas há poesia. Ela não deseja se esconder nos meandros da escrita. Mas ela está lá. Ela não se mostra a todos, mas se derrama sobre os olhos do bom intérprete ou, como sempre dirá, aos seus leitores, Jorge Luis Borges (1989): bons leitores, tão raros quanto os bons escritores. Toda teoria é uma poesia, uma expressão de arte. Toda leitura do mundo também o é, quando criativa, inovadora, crítica e, sobretudo, quando rica de metáforas como deseja Gonçalo M. Tavares (2006). Esta é uma das variadas vias encontradas pelo autor para assumir o reencantamento pela vida, em que a arte e ciência sejam juntas, diversas e complementares, a voz dos terrenos do mundo ou das esquinas variadas das cidades incapazes ou dos mundos incapazes.

Nesta obra, o pensador das humanidades, Boaventura de Sousa Santos - não apenas teórico, mas ativista social - incorpora em suas práticas científicas a poesia, a arte e a emoção, intrínsecas ao compreender das formas de expressão impressas no espaço pelo viver humano nos lugares da cidade. Talvez, o inverso também poderá ser uma expressão da leitura: a poesia incorpora a ciência, abraçando-a como se nunca estivessem separadas. Os poemas expressam o cotidiano dos lugares, a arte dos lugares que estão na contramão do processo de globalização hegemônica. Através da linguagem poética é possível complementar as 
teorias contra-hegemônicas propostas pelo cientista social em seus exercícios e desenhos epistemológicos.

Boaventura de Sousa Santos, solidário com as lutas do mundo, busca a flexibilidade da propriedade intelectual, e propõe alternativas à globalização neoliberal. Para o autor, são diferentes conjuntos de relações sociais que geram diferentes tipos de globalização, que ele prefere, abertamente, chamar de globalizações (SANTOS, B., 2006). São nas cidades que se materializam os processos das globalizações através da impressão do dinamismo das atuações humanas nos lugares, que acabam se submetendo a processos ora de padronização, ora de segregação. Contudo, o desejo de vivenciar o mundo, de dar uma identidade ao projeto de reinvenção da cidadania, de mostrar ao mundo a maneira própria de enxergar a vida, de tornar a rotina e os fazeres comuns uma existência plena, só é possível através da experimentação dos lugares.

O poeta anuncia o tipo da cidade moderna na contemporaneidade: veloz, efêmera, descartável, volúvel, poluída. As cidades modernas são, preferencialmente, do mundo ocidental, capturadas e que se deixam capturar pelas perversidades do globalismo localizado, termo que o autor utiliza em sua teoria social para descrever aqueles lugares onde "as condições locais são desintegradas, marginalizadas, excluídas, desestruturadas e, eventualmente, reestruturadas sob a forma de inclusão subalterna” (SANTOS, B., 2006, p. 438). Isso nos remete à prevalência de relações superficiais, em que a cidadania é órfã de atitudes, os sujeitos não se sentem envolvidos, responsáveis, pertencentes, donos do espaço onde atuam e se relacionam. Essa cidade moderna, hiper-moderna, plena de marcas que não se cicatrizam, de desigualdades e exclusões, toma as delicadezas da vida e nos assalta a partir da imposição de sua velocidade - que impede o encontro, que nos faz apressados, sempre de passagem e em dívida com o tempo e o capital.

Há de se compreender a coerência e a crítica, quando Boaventura de Sousa Santos apresenta, no lugar do prefácio um desfácio, por onde propõe que a sua poesia sirva de títulos para que outros artistas recriem sobre a sua arte: "Pretende apenas provocar a imaginação artística dos outros e servir-lhe de matéria-prima” (SANTOS, 2004, p. 12). Assim, ele legitima o que fundamenta a sua teoria social na luta pela flexibilidade da propriedade intelectual. O desejado é que a Escrita INKZ seja "um antimovimento pela eliminação de todos os monopólios artísticos” (SANTOS, 2004, p. 14). Diz: "Enquanto artista incapaz, quero que a minha 
imaginação suba ou desça ao nível da de todos, não para ser acessível, mas antes para não se distinguir" (SANTOS, 2004, p. 12). Em sua arte-teoria e a sua arte-poesia incapaz, é possível encontrar a voz dos movimentos contra-hegemônicos por ele proclamados. Ambos se apresentam sob a forma de ausências e emergências: "A Escrita INKZ é uma arte incapaz porque só existe sob a forma de ausência ou emergência” (SANTOS, 2004, p 14).

Boaventura de Sousa Santos tenta nos remeter à beleza de ser do lugar no tempo, quando escreve: "Na montra das livrarias do pasmo / A consagração de todos os encantos diários” (SANTOS, B., 2004, p. 118) e que Milton Santos ratifica, ainda que de forma diferente: é no mundo das coexistências, onde tudo se entrelaça, incluindo espaço e tempo, que os valores são refeitos e construídos "[...] através de um constante processo de interação” (SANTOS, M., 1996, p. 253), dando a idéia de que cooperação e conflito, todo o tempo, são a base da vida comum, consagrados no cotidiano. Ali se fundem, materializam, dão forma à memória que não está apenas na mente, mas, sim, grafadas nos lugares, nos corpos-paisagem, nos lugares-cotidianos e nos territórios de possibilidades.

A cidade incapaz mostra-se uma ausência a emergir. Tal como a maçã e o verme, a cidade incapaz e a cidade da pressa ou da razão foram se fazendo, umas as outras, como se, dialeticamente, pertencessem ao mesmo mundo. No entanto, enquanto uma se dá a ver, a outra, incapaz, a cidade da criação que subverte, põe-se às margens. A cidade incapaz é a mais expressiva de todas as possibilidades de reinvenção da cidade dos homens de cidadania, pelo desejo de transformação que faz a existência dos homens lentos - homens do Sul Global - , nos interiores da cidade do desfazer. Ela carrega, em si, a natureza do fazer, das práticas, dos cotidianos e lutas, das artes de cidade que requerem a lentidão ou um tempo próprio que interrogue as pressas e os vazios. A escrita da cidade a nos devolver o perdido lugar das palavras de encontro estará, assim, próxima da escrita incapaz, incompleta - e que, assim, se reconhece que se vai fazendo aberta, permitindo a existência dos outros em nós para que possamos existir.

\section{INCAPABLE CITIES}

Abstract: The city carries many definitions within it. This is so because there are cities of all kinds and there also cities inside cities. The city is the most expressive of places which, on their turn, express the world. The 
world is actualized in places and the city is the world which expresses itself in the most intense way. The city is designed by means of the arts of doing. However, the modern globalized city is the expression of a forked world. Thus, the modern city, predominantly one of mismatches and undoing - the city of immediate discarding - may be understood as the contradictory and dialectic expression of, on the one hand, hegemonic worlds of rationality, and, on the other hand, of art doings: worlds that negate themselves and exist by virtue of such denial. The modern city is the place of haste questioned, within it, by incapable cities, the city of slow humans. Incapable cities are the places of indignation, the desire to change, the assumed incompleteness which, paradoxically, prolongs itself as the art of living reproduces itself.

Key words: cities, the writing of cities, city and literature, INKZ writing, incapable cities.

\section{BIBLIOGRAFIA}

BARTHES, Roland. Aula. 13 ed. São Paulo: Cultrix, 2007.

BORGES, Jorge Luís. História universal da infâmia. 5. ed. São Paulo: Globo, 1989.

CALVINO. Italo. Seis propostas para o próximo milênio: lições americanas. São Paulo. Companhia das letras, 1990,

HISSA, Cássio Eduardo Viana. Mobilidade das fronteiras: inserções da geografia na crise da modernidade. Belo Horizonte. Ed. UFMG, 2002.

HISSA, Cássio Eduardo Viana. Cidade e ambiente: dicotomias e transversalidades. In: HISSA, Cássio Eduardo Viana. (Org.). Saberes ambientais: desafios para o conhecimento disciplinar. Belo Horizonte. Ed. UFMG, 2008. p. 259-281.

HISSA, Cássio Eduardo Viana. Território de diálogos possíveis. In: RIBEIRO, Maria Teresa Franco; MILANI, Carlos Roberto Sanchez. (Org.). Compreendendo a complexidade socioespacial contemporânea: o território como categoria de diálogo interdisciplinar. Salvador: EDUFBA, 2009. p. 36-84.

MATURANA, Humberto. A ontologia da realidade. Belo Horizonte: Ed. UFMG, 1997.

MATURANA, Humberto. Emoções e linguagem na educação e na política. Belo Horizonte: Ed. UFMG, 1998. 
PRADO JÚNIOR, Bento. Erro, ilusão, loucura. In: NOVAES, Adauto (Org.). A crise da razão. São Paulo: Companhia das Letras, 1996. p. 111-133.

SANTOS. Boaventura de Sousa. Escrita INKZ: anti-manifesto para uma arte incapaz. Rio de Janeiro: Aeroplano, 2004.

SANTOS, Boaventura de Sousa. Escrita INKZ. [Entrevista concedida a Christian Schwartz]. Disponível em: <http://www.ces.uc.pt>. Acesso em: 15 nov. 2008.

SANTOS. Boaventura de Sousa. A gramática do tempo: para uma nova cultura política. São Paulo: Cortez, 2006.SANTOS, Milton. A natureza do espaço: técnica e tempo; razão e emoção. São Paulo: HUCITEC, 1996.

SANTOS, Milton. Da totalidade ao lugar. São Paulo: Edusp, 2005.

SANTOS, Milton. O mundo não existe. Veja. [Entrevista com Dorrit Harazim], ano 27, n. 46, 16 de novembro de 1994. p. 7-10.

SANTOS, Milton. Território e sociedade. São Paulo: Fundação Perseu Abramo, 2000.

TAVARES, Gonçalo M. Breves notas sobre ciência. Lisboa: Relógio D’Água, 2006. 